\title{
PSICOPATOLOGIA DA RECESSÃO E DO DESEMPREGO
}

Edith Seligmann-Silva*

\section{Considerações Gerais}

os períodos de recessão o sofrimento social, o sofrimento físico e o sofrimento mental geralmente são indissociáveis, muito embora muitas vezes tenham sido estudados em forma compartimentada e reducionista.

BRENNER e MOONEY (1982) investigaram como as mudanças econômicas, tanto nas fases de crescimento quanto nas de recessão, têm afetado a saúde humana e, de modo especial, a saúde mental e a mortalidade por doenças cardiovasculares.

O desemprego, por mais paradoxal que isso possa parecer, em verdade tem merecido pesquisas mais abrangentes e detalhadas nos países ricos do que no Brasil. Assim, um recente estudo realizado na Holanda examinou importantes aspectos psicossociais relacionados com os reflexos do desemprego sobre a saúde coletiva, identificando alguns fatores stressantes relacionados com a deterioração da saúde e diferenciando-os segundo contexto urbano e contexto rural(11).

Nos paises onde as condições de trabalho e a organização do mesmo tem tido repercussões fortemente negativas para a saúde dos empregados, são especialmente importantes as desvantagens que se apresentam para os trabalhadores considerados como não qualificados.

Enquanto se desenvolve a escalada mundial do desemprego, duas observações que vêm emergindo de diferentes investigações devem ser de início aqui assinaladas. Ambas dizem respeito à questão da correlação desemprego e alterações da saúde.

Em primeiro lugar, tem havido concordância em relação ao fato de que os riscos de desemprego aumentam para as pessoas que já apresentam manifestações de desgaste psíquico ou psico-orgânico(6) (16) (20). Em segundo lugar, existe um risco maior de que o desemprego assuma longa duração para estas pessoas, pois as alterações de saúde resultam em desvantagem na concorrência às vagas do mercado de trabalho.

$\mathrm{O}$ agravamento concomitante da pobreza e da deterioração da saúde dos desempregados e de suas famílias vem sendo verificado nos países em que a progressão do desemprego não tem sido acompanhada de políticas sociais suficientes para garantir aos desempregados condições de subsistência compatíveis com suas necessidades essenciais nem perspectivas de apoio para a reinserção, a curto ou médio prazo, no mercado de trabalho.

\section{A Dimensão Psicossocial e os Distúrbios Mentais no Desemprego}

São já numerosos os estudos que têm sido realizados, em regiões e em países afetados pelo desemprego com respeito às repercussões do mesmo na saúde mental dos desempregados. Há falta ainda, entretanto, de estudos que, utilizando uma mesma metodologia, permitam a realização de análises comparativas entre distintos contextos nacionais diferenciados segundo condições políticas, sócio-econômicase culturais.

A existência de uma relação clara entre as diferentes etapas do desemprego e do tipo de distúrbio psíquico ou psicossocial é verificada por diferentes estudos. Eisenberg e Lazarsfeld, já em 1938, registraram: "Todos os autores que escrevem sobre o desemprego estão de acordo sobre os seguintes pontos: existe de início um choque, o qual é seguido por uma fase de procura febril de um emprego, no curso da qual o indivíduo é otimista e ainda não se mostra conformado; ele conserva uma atitude resoluta. Em sequência, depois de terem fracassado todos os seus esforços, $\mathrm{o}$ indivíduo se torna pessimista e ansioso, situando-se à beira de um profundo transtorno. Esta etapa é a mais crítica de todas. Ao final, o indivíduo se torna fatalista e se adaptaà sua nova situação, porém com limitações. Ele passa a ter uma atitude submissa."

SPRUIT et al. (1985) constataram diferenças significativas na prevalência de distúrbios mentais entre empregados e desempregados, num estudo epidemiológico do qual foram excluídos da amostra aqueles desempregados 
que antes do desemprego já tivessem apresentado transtorno psíquico.

A correlação entre desemprego e transtorno mental é também confirmada pelas pesquisas que demonstram que pessoas que haviam apresentado manifestações psicopatológicas no decurso da experiência de desemprego tiveram remissão dos sintomas ao obterem novo trabalho. (Jackson et al., 1983.)

\section{Desemprego, Pobreza e Trabalho não Qualificado}

WHELAN (1992) publicou os resultados de estudo realizado na Irlanda, em nível nacional. Esta pesquisa permitiu analisar diferenças de risco mental no desemprego conforme inserção social. O nível prévio de renda e o grau de qualificação profissional constituiram-se variáveis importantes na explicação das diferenças encontradas. Quanto maior a pobreza e quanto menos qualificado profissionalmente $o$ indivíduo, maiores as chances de agravo mental. $\mathrm{O}$ estado geral de saúde também esteve fortemente associado às desvantagens apresentadas pelos indivíduos dos estratos sociais de maior pobreza.

O mesmo autor aponta alguns pontos de grande interesse. Assinala, assim, que mesmo sendo o próprio desemprego uma causa importante de pobreza, deve ser lembrado que o distúrbio mental que surge entre pobres desempregados não pode ser atribuído apenas ao agravamento da situação de pobreza. Pois o papel do trabalho na integração do indivíduo em uma rede de relações sociais é também de alto significado para o favorecimento da saúde mental. Deste modo, Whelan analisa as repercussões psicopatológicas do desemprego em pessoas de camadas sociais acima da faixa de pobreza. A pesquisa irlandesa mostrou que "os desempregados não pobres possuem cinco vezes mais chances de transtorno psíquico que pessoas dos mesmos níveis que estejam empregadas ou aposentadas. Entretanto, nossos resultados mostram claramente que o impacto do desemprego aumenta significativamente para os pobres: uma pessoa em catorze, entre os não pobres empregados ou aposentados, apresenta transtorno mental, enquanto a taxa se eleva a mais de dois sobre cinco para os que são vítimas simultaneamente do desemprego e da pobreza."'(pg.182)

\section{Risco de Suicídio nas Situações de Desemprego}

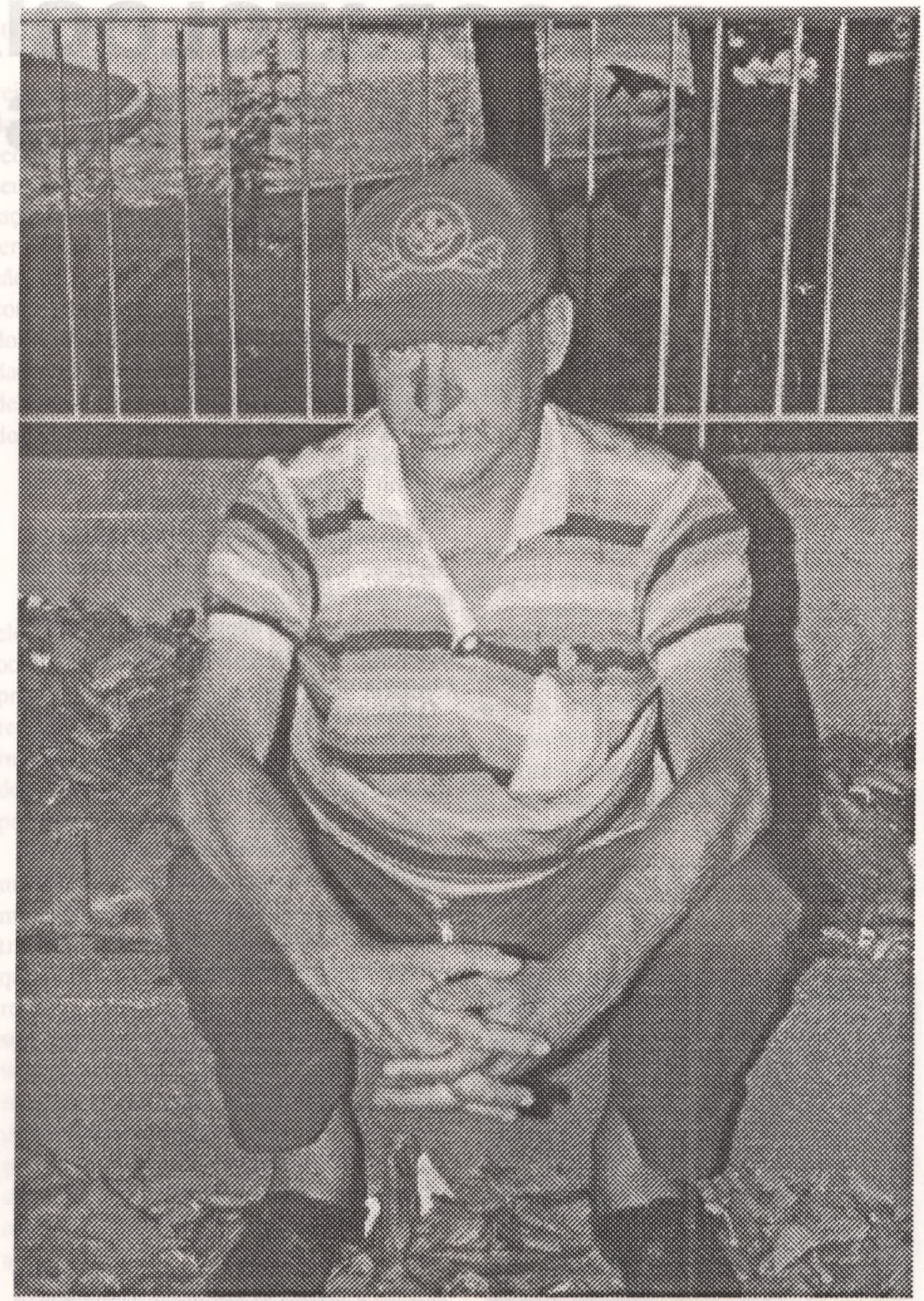

Foto: Suzuki

Diferentes pesquisadores investigaram as relações entre desemprego e suicídio, em vários países, ao longo de diferentes períodos que incluíram fases de recessão econômica.

FRIED (1966) e PHILIPPE (1990) realizaram revisões da literatura médica sobre o assunto e efetivaram pesquisas epidemiológicas, estudando estatisticamente o risco de suicídio em sua correlação ao desemprego. É importante assinalar que nas pesquisas mais recentes, Philippe, durante os anos 80 , na França, distinguiu os casos e tentativas de suicídio de pessoas sem e com antecedentes psiquiátricos, constatando que a situação de desemprego se configura realmente como um fator de risco. Os grupos em que houve maior incidência foram os correspondentes a pessoas jovens, solteiras, divorciadas ou separadas. As taxas foram maiores para os desempregados do sexo masculino.

As conclusões deste estudo realizado por Philippe sobre a gravidade do risco de suicídio na situação de desemprego, atualizam as observações de Fried, referidas a um periodo de cerca de 50 anos antes, levando-nos a pensar que, não obstante todas as transformações sociais, econômicas e políticas de meio século, o significado do desemprego continua carre- 
gando em seu bojo conotações a tal ponto desalentadoras, que o risco de desencadear sentimentos e ações de desespero - dentre as quais ressalta o suicídio -, permanece perigosamente intenso.

\section{O Desgaste na Saúde nos Critérios Demissionais}

O estado de saúde individual pesa nos critérios adotados pelas empresas para tomar decisões quanto a quem perderá o emprego, quando se trata de operacionalizar cortes de pessoal nas reformulações organizacionais e tecnológicas(5) (6) (16) (20).

Ao longo da trajetória ocupacional, isto é, da vida de trabalho de cada assalariado, acontece um acúmulo de desgastes sempre que as características do trabalho sejam agressivas à saúde. Deste modo, dependendo do tempo de permanência em empregos desgastantes, o próprio processo natural de envelhecimento pode ser acelerado e intensificado.

Assim, na efetivação dos "enxugamentos" prescritos pelos princípios administrativos de racionalização, serão justamente os empregados mais desgastados aqueles que primeiro serão sacrificados em nome da produtividade, ou, mais contemporaneamente, de uma "qualidade total" onde corpos e mentes já prejudicados não têm mais lugar.

DESSORS, SCHRAM e VOLKOFF (1990) esclarecem a forma pela qual vai se processando o desencontro entre novas exigências empresariais e uma desqualificação que se associa à corrosão da saúde. O título do estudo é bastante elucidativo: "Da 'desvantagem de situação' à seleção-exclusão: um estudo das condições de trabalho anteriores às dispensas econômicas ". Trata-se de uma investigação que mostra, em primeiro lugar, que a causa econômica ou tecnológica das demissões corresponde a critérios em que o que alguns economistas denominam "capital humano" é reduzido à condição de instrumento. $\mathrm{O}$ que significa que a avaliação destes " instrumentos" deverá analisar suas "condições objetivas" tendo em vista a eficácia dos mesmos para que sejam alcançadas determinadas metas de produção. Portanto, quando se trata de promover cortes para, na recessão, restringir despesa com salários e concentrar a produção no esforço de um número menor de empregados, o nível de desgaste e a idade, conjuntamente, configuram um critério para a tomada de dicisão referente a "demitir ou conservar", A lógica do critério é simples: pressupõe-se que só os em melhores condições de saúde intensificarão a produção.
Quando se trata de um empregado não especializado, nos momentos de renovação tecnológica e/ou introdução de novas práticas de organização do trabalho, a "descartabilidade" e substituição do trabalhador se baseará num conjunto um pouco mais complexo de atributos, onde à avaliação do estado de saúde e da idade se acrescenta a análise da medida em que o empregado é "reciclável" com fins de atender às novas exigências da modernização. Assim, integradamente ao grau de desgaste, o nivel de qualificação pesará nas decisões(5).

O estado de saúde também pesa quando se trata de encontrar um novo emprego. Um estudo realizado na ex-Alemanha Ocidental (República Federal da Alemanha) ao longo do periodo 1984-1988, pelo DIW (Instituto Alemão de Pesquisas Econômicas), acompanhou ano a ano a situação de 5.516 pessoas entre 18 e 64 anos de idade. ELKELES e SEIFERT (1993) com base neste estudo longitudinal, analisaram a correlação entre estado de saúde e desemprego. Concluiram que a deterioração da saúde se constitui em importante fator nos critérios demissionais. Esse estudo constatou, entre outras verificações, as seguintes:

1) Os assalariados cuja saúde havia sofrido mais agravos foram também os que mais perderam seus empregos; 2) Dentre as pessoas que haviam ficado desempregadas, as que obtiveram novos empregos foram predominantemente as mais saudáveis; 3) Em contrapartida, os desempregados portadores de perturbações da saúde foram os que, proporcionalmente, mais permaneceram na situação de desemprego; 4) Não foi constatada relação causal de situação de desemprego ocasionando deterioração da saúde.

Esta última conclusão, se por um lado contraria outros estudos sobre o assunto, pelo outro nos conduz a importantes reflexões quanto às distinções quenecessariamente devem serconsideradas entre os contextos (sócio-econômi$\cos$, políticos e culturais) quanto ao favorecimento desta causalidade.

Não seria possível, neste artigo, analisar todos os aspectos que se entrelaçam na determinação destas diferenças. Entretanto, pode ser afirmado que a percepção da situação e o grau de esperança quanto à superação do desemprego dependerão em grande parte destas mesmas diferenças. As condições de vida durante o desemprego, a auto-imagem e a dignidade do desempregado, são outros tantos aspectos que por um lado estando fortemente determinados por esse contexto, irão pelo outro repercutir na dinâmica psicossocial e psicossomática dos processos que levam ao fortalecimento da saúde ou às manifestações de doenças.

\section{A Situação Latino-Americana e o Brasil}

As complexas dinâmicas psicoculturais que acompanham a recessão, merecem certamente estudos especiais no contexto mais amplo da América Latina, para uma compreensão mais clara de como outros fenômenos sociais fortemente preocupantes - como a violência e também o consumo de bebidas alcoólicas e de drogas - se interrelacionam com o desemprego e com as recessões prolongadas, em mecanismos que passam, inexoravelmente, pelo empobrecimento, pela corrosão da identidade social e pelo dilaceramento de esperanças individuais e coletivas.

MARTÍN BARÓ (1983), analisando a importância do trabalho na construção da identidade e como núcleo ao redor do qual o indivíduo desenvolve significado para a própria vida, observa, entretanto, que na realidade latinoamericana a situação obriga a encarar aspectos muito dramáticos: "Precisamente porque o trabalho desempenha um papel tão crucial na definição da existência pessoal, naquilo que uma pessoa pode chegar a ser mediante aquilo que faz, resulta tão grave a falta generalizada de trabalho que se apresenta como situação habitual para uma maioria de latino-americanos. Em El Salvador, as taxas reais de desemprego da popoulação economicamente ativa chegaram em anos recentes a níveis superiores a $50 \%$, e esta trágica realidade chega apenas a ser esmaecida pelo emprego temporário e pelas formas marginais de subemprego. Assim, o primeiro problema que se apresenta a um setor muito grande da população salvadorenha é ode encontrar trabalho, e apenas em segundo lugar o de desenvolver-se pessoalmente no trabalho que lhe seja acessivel (...). A busca continuada de emprego é a principal ocupação do salvadorenho médio e certamente sua mais profunda preocupação. Unicamente a seguir, para aquele que possui trabalho assegurado, é que se coloca o problema do "sentido laboral''(p.186).

\section{Chile - Observações num contexto de Ditadura Militar}

LIRA e WEINSTEIN (1980) estudando no Chile, ao longo de vários anos em acompanhamento psicológico, pessoas desempregadas, desenvolvem importante revisão do assunto, delineando, inclusive as etapas pelas quais evolui a "psicopatologia do desemprego", num contexto em que as possibilidades de 


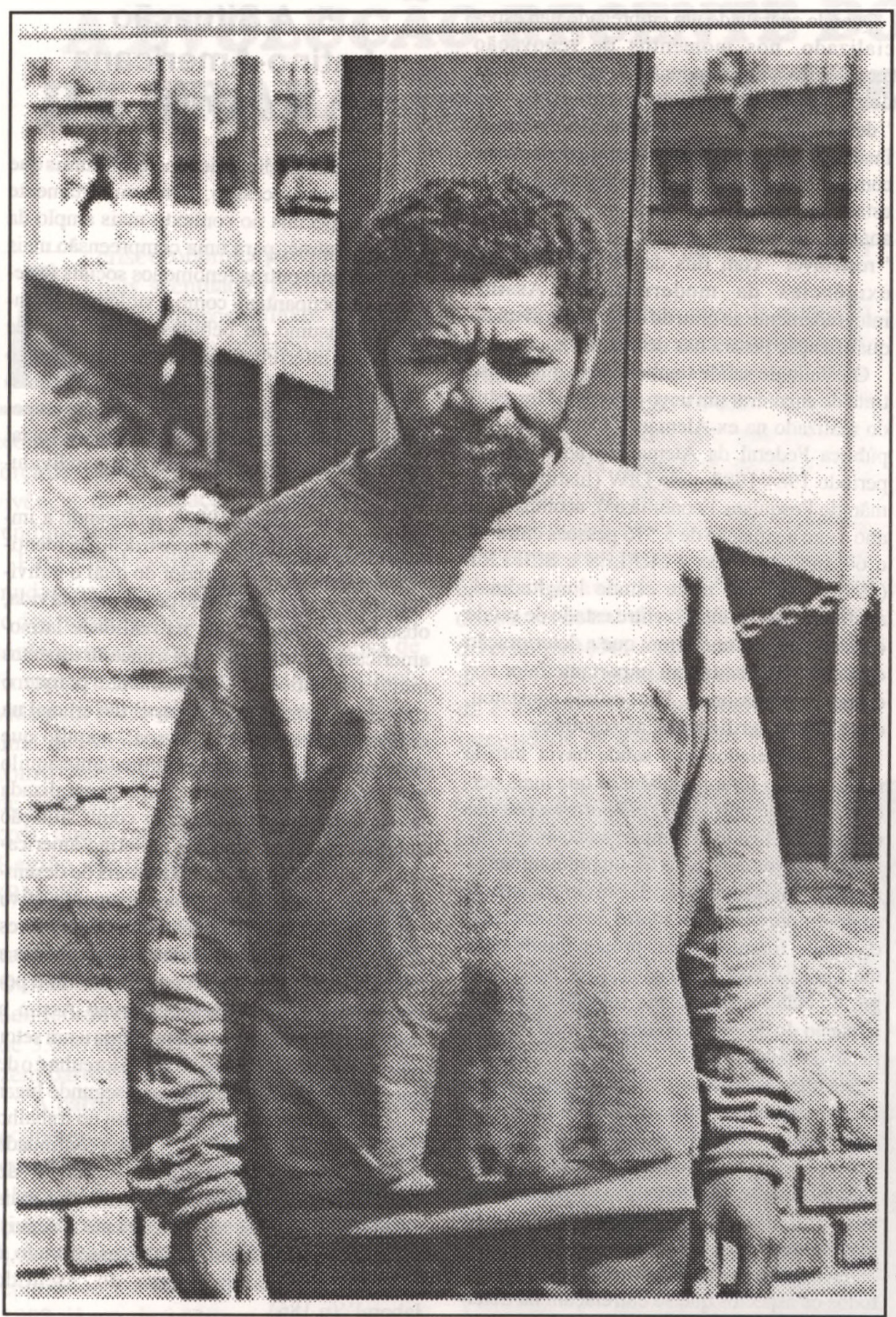

Foto: Pedrão

enfrentamento político e de ações solidárias organizadas se tornaram impedidas por forte estrutura repressiva. Considerando o trabalho como uma instância primordial da relação entre o indivíduo e a sociedade, além de suporte fundamental da própria identidade, forma de expressão de capacidades e fonte de subsistência material, as autoras constatam: " a desarticulação da prática social, decorrente do desemprego, deixa um vazio que gera desequilibrio no espaço interno das relações vulnerável e fragilizado;

2) Sensação de esvaziamento do sentido da própria vida;

3) Perda de pontos de referência para programar o cotidiano;

4) Isolamento social, em que "o indivíduo se sente só, abandonado e excluído",

A partir das observações realizadas nas pessoas desempregadas cujo acompanhamento realizaram, as mesmas autoras chilenas conseguiram identificar, também, aspectos psicodinâmicos vinculados à alienação e à frustração decorrentes do desemprego, detectando, como consequências principais, quatro respostas psicológicas básicas, cuja dinâmica e reflexo na vida familiar e na atitude face à sociedade e a si mesmo as autoras analisam. Estas respostas surgiram geralmente dentro da seguinte sequência: a)Agressão; b) Regressão; c) Fixação (comportamento rígido, estereotipado); d) Apatia.

No momento em que vivemos, a preocupação com a violência torna especialmente relevante o que as autoras mencionam com respeito à agressão: Freud foi um dos primeiros a assinalar que a cólera que se segue às experiências frustradoras pode ser projetada pelo indivíduo sob formas muito diversas. Pode ser dirigida ao objeto que a produziu, o que no caso do desemprego seria o sistema social. Porém, se este direcionamento da agressão é impossibilitado, em parte pela natureza do objeto (difuso, onipotente) ou das respostas que possam ser esperadas do mesmo (represálias, outras agressões, etc.), é produzido um deslocamento.

Dentro do sistema político autoritário-punitivo, onde os canais de protesto e encaminhamento de reivindicações da população em geral, e portanto, também das massas desempregadas, se encontram rompidos, as autoras constataram a frequência do deslocamento da agressividade. Ador/frustraçãoocasionada pelo desemprego/impotência para luta eficaz, conduziram, de forma infeliz, a ataques dirigidos contra a própria família, ou, também com frequência, à auto-agressão. Ou, ainda, a atos delinquenciais dirigidos ao meio circundante.

A repercussão da frustração/agressão em nível do relacionamento conjugal, é muito bem explicitada pelas autoras: " $O$ desemprego prolongado vai gerando uma série de condições que alteram o modo de vida do grupo familiar. Surge a instabilidade emocional, ocorrem acusações recíprocas entre os cônjuges, um exige do outro mais do que pode ser dado. As carências vão se tornando cumulativas, uma vez que para comer torna-se necessário vender e empenhar objetos, o que vai reduzindo o mundo das coisas que compõe um lar. O que resta vai sendo marcado pela pobreza-a roupa de pobre, 
a casa de pobre, a comida de pobre - o que vai estruturando uma identidade de pobre, de pessoas desvalorizadas."

Prosseguem as autoras, demonstrando como a experiência de desemprego prolongado pode originar ao mesmo tempo, reações patológicas e transformações na identidade social. A ruptura do projeto de vida assume papel marcante nestes processos. $\mathrm{O}$ alheamento, em que o indivíduo se sente separado de tudo o que era antes, pode emergir.

Seria neste ponto que ocorreria uma ruptura muitas vezes do tipo psicótico, isto é, a loucura. Ela surge, assim, no momento final resultante de todo um processo de deterioração dos principais parâmetros da identidade, que se desenvolve ao longo do desemprego prolongado. Este processo de gradual destruição da identidade é estudado também pelas autoras citadas. Alguns dos aspectos que ressaltam dentro deste processo, são: a forma pela qual o projeto de vida individual e o ideal de si mesmo são duramente confrontados com as práticas, papéis e valorizações sociais experimentadas pelo indivíduo; a resultante queda da autoestima; a quebrada identidade ocupacional, em verdade indissociável da identidade global, o surgimento de uma identidade negativa, produto da dissolução patológica dos "vínculos de integração da identidade" considerados pelas autoras. Essa "identidade negativa" estaria representada por uma situação de dupla carência: ausência de atividade laboral e ausência de recursos indispensáveis para o sustento familiar.

As fases do processo psicopatológico descrito pelas autoras corresponde, em suas linhas gerais, aos especificados por outros autores, mas apresentam peculiaridades que refletem a repressão política da época.

Nas conclusões do impressionante relato de Lira e Weinstein ressalta claramente uma diferença marcante entre o desemprego dos países pobres e o desemprego dos países ricos: a pobreza passa a constituir-se um agravante de enorme poder para a eclosão das doenças em geral, e muito especialmente para aquelas que se desencadeiam a partir da agressão ao psiquismo, quando são atacadas a identidade e as perspectivas de manter projetos de vida digna.

\section{Recessão e a Psicopatologia do Desemprego no Brasil}

Inexiste, até o momento, a publicação de uma pesquisa extensa sobre a interrelação desemprego-saúde mental no Brasil.
Na recessão do início dos anos 80 tivemos ocasião de estudar as formas pelas quais aumentou, então, o desgaste mental de trabalhadores industriais que ainda mantinham seus empregos. Considerando-se que muitos vieram, posteriormente, a perder estes empregos, pode-se, a partir daí, considerar a fragilização ocorrida imediatamente antes do advento do desemprego como importante aspecto a merecer atenção na análise da situação dos desempregados.

De modo geral, nos estudos de casos então realizados verificamos uma exacerbação do cansaço e das tensões, ocasionada pelo aumento das exigências e pressões exercidas sobre estes trabalhadores durante a recessão. No esforço de maximizar a produtividade ao longo da crise, as empresas haviam modificado as condições materiais e organizacionais do trabalho, tendo ocorrido, mais notadamente além das dispensas maciças que resultaram em sobrecarga de trabalho para os empregados remanescentes: prolongamento das jornadas de trabalho, que nem sempre eram acompanhadas por pagamento de horas-extras; intensificação do ritmo de produção; acúmulo de funções para um mesmo assalariado; restrição do número e da duração das pausas, em certos casos até com supressão completa das mesmas; desvios de função (que, por falta de treinamento, resultavam muitas vezes em aumento dos riscos de acidente) e maior utilização, pelas firmas, do regime de trabalho em turnos alternados.

Além disso, ocorria uma compressão de despesas, em que as empresas procuravam economizar às custas da diminuição dos gastos com pessoal de manutenção e de limpeza, equipamentos de proteção, refeições, leite e substituição de ferramentas desgastadas. Em tais circunstâncias, obviamente, aumentavam os esforços, os riscos enfrentados e, por consequência, também o cansaço e a ansiedade. Esta ansiedade tinha muitos conteúdos, sendo feita, geralmente de diferentes medos: o medo de acidentes, tornados mais prováveis nas situações descritas; o medo de não resistir ao cansaço e desgaste percebidos, passando a render menos ou adoecendo; o medo, sobretudo, de perder o emprego.

A intensificação dos conflitos, quer entre trabalhadores e suas chefias, quer entre companheiros de trabalho, foi outro aspecto observado como contribuindo para o aumento das tensões.

Na mesma fase recessiva, realizamos também estudos de casos em que trabalhadores desempregados haviam tido desencadeamento de sintomatologia psiquiátrica ou psicossomática, e nos quais a análise integrada dos eventos de vida, trabalho e aspectos clínicos permitiu identificar fenômenos cu- mulativos pelos quais o processo de desgaste se havia acentuado ao longo de etapas sucessivas da vida laboral e, depois, da situação de desemprego. Em geral, nestes casos estudados, o desgaste mental - que se expressava mais frequentemente através de manifestações de tipo depressivo, estava associado a outros transtornos de saúde, destacando-se ai a hipertensão arterial e distúrbios do aparelho digestivo (17).

Nos casos estudados, o choque inicial, por ocasião da dispensa, configurou-se para alguns como verdadeiro trauma, resultando o aparecimento, depois, de manifestações de inquietação, insônia e do reviver mentalmente, de modo repetido e frequente, o episódio da dispensa. Este conjunto de sintomas, é o que costuma caracterizar a chamada neurose traumática.

A percepção da própria saúde estava alterada, agravando a ansiedade dos desempregados, que se preocupavam vivamente quanto às restrições que tal estado acarretaria para a aceitação de um novo emprego. Em vários casos, além dos distúrbios que percebiam em si mesmos, os trabalhadores se preocupavampela ocorrência de doenças em seus familiares, para as quais não podiam obter assistência médica adequada.

Neste estudo, foi possível encontrar muitos pontos de semelhança, nos aspectos da dinâmica psicológica, com os estudos já mencionados de outros autores, e muito especialmente com o que foi relatado por Lira e Weinstein (1980).

No Brasil, ainda na recessão do começo dos anos 80,CAMON(1986)estudou tentativas de suicídio analisadas no período $80-83$, consta-

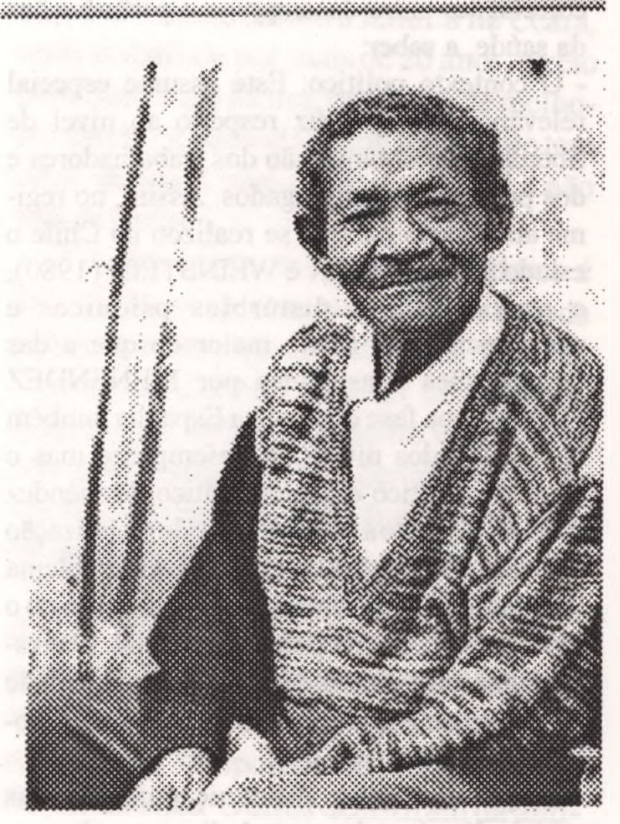

Foto: Alderon P. da Costa - CDCM 
tando que ao longo dessa fase, anualmente aumentou a proporção de tentativas em que o desemprego foi mencionado como causa pelos pacientes atendidos em serviços de emergência de vários hospitais, na cidade de São Paulo.(2)

Na revisão que procuramos realizar sobre o assunto, não encontramos estudos brasileiros que avaliassem estatisticamente a correlação estado de saúde / risco de desemprego ou analisado os critérios demissionais referidos aos transtornos da saúde mental ou geral.

Entretanto, pode ser esperado que, em periodos de recessão, também no Brasil o incrivel aumento de candidados às vagas do mercado de trabalho piore as chances dos desempregados desgastados de obterem novamente empregos. De onde se pode cogitar que, ao mesmo tempo que tiveram precedência na "seleção para demissão", são estes os desempregados que devem ter mais graves perspectivas de um desemprego prolongado.

Cabe ainda lembrar que a utilização da rotulação psiquiátrica como estratégia de sobrevivência foi constatada por alguns estudos realizados antes do advento do seguro-desemprego. $\mathrm{O}$ que significa que trabalhadores desempregados buscaram um diagnóstico psiquiátrico ou mesmo uma hospitalização psiquiátrica para garantir sua subsistência e a de seus familiares (3) (8) (10).

\section{Considerações Conclusivas}

Ao concluir, queremos ressaltar três aspectos a serem considerados quando da análise das correlações entre desemprego e perturbações da saúde, a saber:

- O contexto político: Este assume especial relevância no que diz respeito ao nível de liberdade de organização dos trabalhadores e dos próprios desempregados. Assim, no regime autoritário em que se realizou no Chile o estudo feito por LIRA e WEINSTEIN (1980), a gravidade dos distúrbios psíquicos e psicossociais foi muito maior do que a das perturbações constatadas por MENENDEZ (1984) numa fase em que na Espanha também havia elevados níveis de desemprego mas o contexto político era democrático. Menendez assinala oquanto a possibilidade de mobilização na busca de soluções coletivas para o problema do desemprego se torna importante, evitando o desenvolvimento de patologia mental. $\mathrm{O}$ mesmo autor mostra também como a possibilidade de quaisquer ações solidárias neutraliza o isolamento e o desânimo.

- A ação do Estado: A definição de políticas sociais direcionadas ao trabalho e aos desem- pregados, quando de sua implementação permitem que se estabeleça confiança e, portanto, que seja mantida a esperança. Inexistindo condições para que essa confiança e esperança se façam presentes, certamente a situação de desemprego representará maior risco mental, psicossomático e psicossocial.

- O papel da comunicação: As formas pelas quais as questões do trabalho e do desemprego são esclarecidas e discutidas pela sociedade também merecem atenção na análise, pois quando a natureza social do desempregado é amplamente reconhecida, este deixa de ser uma culpa ou um sinal de fracasso individual que leve os desempregados a sentimentos de vergonha e à busca de isolamento.

Por fim, é importante ter presente o fato de que as pessoas que concomitantemente apresentam menor qualificação profissional e maiores complicações em seu estado de saúde - em especial da saúde psicossocial - tendem a constituir um segmento cada vez mais amplo de desempregados entre as populações de países onde se associam: a) recessão prolongada, b) implantaçãode transformações tecnológicas e organizacionais modernizantes, c) politicas sociais insuficientes para prevenir e resolver os problemas de saúde, emprego e qualificação, d) fragilidade e lentidão no amadurecimento da cidadania.

Diante do exposto, cabe pois uma séria reflexão por parte de todos aqueles que carregam a responsabilidade social com respeito às políticas que provocam e agravam o desemprego, bem como àquelas outras que poderiam assegurar melhor qualidade de vida tanto aos que ainda trabalham, quanto aos que já perderam seus empregos.

"Edith Seligmann-Silvaé Professora no Dpto. de Medicina Preventiva da Faculdade de Medicina da USP e na Escola de Administraçăo de Empresas (EAESP FGV)

\section{Referências Bibliográficas}

1) BRENNER, M.H. e MOONEY, A. - Economic Change and sex-especificcardiovascular mortality in Britain 1955-76 - Soc. Sci. Med. 16:431-442, 1982.

2) CAMON, V.A.A. - Como uma sociedade suicida aniquila suas vítimas: A Saúde Mental no Brasil- In ANGERAMI-CAMON(Org.) Crise, Trabalho e Saúde Mental no Brasil, ed. Traço, 133. 150, S.Paulo, 1986.

3) DELGADO, P.G.G. - Mal-estar na indústria Dissertaçāo deMestrado-Instituto de Psiquiatrial UFAJ, 1983.

4) DEJOURS, C. - Réactions psychopathologiques aux ruptures involuntaires d'activité profissionnelle - Psychologie Médicale,
15 (11): $1875-1880$, Paris, 1983.

5) DESSORS, D:; SCHRAM, J. e VOLKOFF, S. - Du "handicap de situation", à la sélectionexclusion: une étude des conditions de travail anterieures aux licenciements économiques Rapport, n.101. Laboratoire d'Ergonomie et de Neurophysiologie du CNAN. Paris, 1990.

6) ELKELES, T. e SEIEERT, W. - Unemployment and Health-Impairments: Longitudinal Anallyses for the Federal Republic of Germany - Relatório de Pesquisa - Social Science Reserch Center Berlin, 17pp.

7) FRIED, M. - Effects of Social change on mental Health - In: BERGEN, B. e THOMAS, C. - Issues and problems in Social Psychiatry-Ed.C. Thomas, pp.358-379, Illinois, 1966.

8) GUEIROS SOUZA, M.C. - 'Doença dos Nervos' como estratégia de sobrevivência-mimeo, 46pp., Recife, 1980.

9) JACKSON et alli. Unemployment and psychological distress in young people: the moderating role of employmentcommitment- J. of applied Psychology, 68, 525-535, 1983.

10) LAURELL, A.C. e SERRANO, M.M. - Crisis y Salud en America Latina - Revista Centro-Americana de la Salud (21): 21-37, Jan-abril, 1982.

11) LEEFLANG, R.L.I.; KLEIN-HESSELINK, D.J. e SPRUIT, I.P. - Health effects of Unemplooyment Soc. Sci. Med. 34(4): 341-363, 1992.

12) LIRA, E. e WEINSTEIN, E. - Desempleo y dano psicológico - 22p. Mimeo. Santiago, 1980. (Apresentado aoll encontro Latino-Americano da Rede de Alternativas à Psiquiatria, Belo Horizonte, 1983).

13) MARTIN-BARÓ, 1. - La Interaccion Personal: Contexto y Percepcion - In MARTIN-BARÓ,I. Acción Y Ideologia, pp.183-235, UCA Ed. EI Salvador, 1990.

14)MENENDEZ, F.P. - Trabajo, miedo al despido y paro, tres graves amenazas del obrero - Coord. Nacional de Trabajadores en paro de Euskadí Sur, pp.40-54, 1984.

15) PHILIPPE, A. - Risque suicidaire et statut professionnel - Revue Trimestrielle du SNPMT (143): 48-51, 1990.

16) RUDOLPH, H. - "RFA-Changement et Diversité"- In BENOIT-GUILBOT, O. et GALLIE, D. (orgs.) - "Chômeurs de longe Durée", pp.105123, Actes-Sud, Arles, 1992.

17) SELIGMANN-SILVA, E. - Crise Econômica, Trabalho e Saúde Mental - In ANGERAMICAMON (Org.), Crise, Trabalho e Saúde Mental no Brasil- Traço Ed., pp.54-132, S.Paulo, 1986.

18) - Desgaste Mental no Trabalho Dominado - Ed. Universidade Federal do Rio de Janeiro, 1993.

19) SPRUIT etalli, - Experiencing unemployment, financial constraints and health-Apud WHELAN, C.T. (referência a seguir).

20) WHELAN, C.T. - Désarrol psychologique et pauvreté en Irlande - In BENOIT-GUILBOT et GALLIE, D. (Orgs.) Chômeurs de longue durée pp. 175-186, Actes Sud, Arles, 1992. 